EGU2020-4710

EGU General Assembly 2020

(c) Author(s) 2020. This work is distributed under

the Creative Commons Attribution 4.0 License.

\title{
Satellite monitoring of mass changes and ground subsidence in Sudan's oil fields using GRACE and Sentinel-1 data
}

\author{
Nureldin Gido ${ }^{1,2}$, Hadi Amin², Mohammad Bagherbandi ${ }^{1,2}$, and Faramarz Nilfouroushan ${ }^{2,3}$ \\ ${ }^{1}$ Royal Institute of Technology (KTH), Division of Geodesy and satellite positioning, Stockholm, Sweden (nureldin@kth.se) \\ ${ }^{2}$ Faculty of Engineering and Sustainable Development, University of Gävle, Gävle, Sweden \\ ${ }^{3}$ Department of Geodetic Infrastructure, Geodata Division, Lantmäteriet, Gävle, Sweden
}

Monitoring environmental hazards, due to natural and anthropogenic causes, is one of the important issues, which requires proper data, models, and cross-validation of the results. The geodetic satellite missions, e.g. the Gravity Recovery and Climate Experiment (GRACE) and Sentinel-1, are very useful in this aspect. GRACE missions are dedicated to model the temporal variations of the Earth's gravity field and mass transportation in the Earth's surface, whereas Sentinel-1 collects Synthetic Aperture Radar (SAR) data which enables us to measure the ground movements accurately. Extraction of large volumes of water and oil decreases the reservoir pressure, form compaction and consequently land subsidence occurs which can be analyzed by both GRACE and Sentinel-1 data. In this paper, large-scale groundwater storage (GWS) changes are studied using the GRACE monthly gravity field models together with different hydrological models over the major oil reservoirs in Sudan, i.e. Heglig, Bamboo, Neem, Diffra and Unity-area oil fields. Then we correlate the results with the available oil wells production data for the period of 2003-2012. In addition, using the only freely available Sentinel-1 data, collected between November 2015 and April 2019, the ground surface deformation associated with this oil and water depletion is studied. Due to the lack of terrestrial geodetic monitoring data in Sudan, the use of GRACE and Sentinel-1 satellite data is very valuable to monitor water and oil storage changes and their associated land subsidence over our region of interest. Our results show that there is a significant correlation between the GRACE-based GWS change and extracted oil and water volumes. The trend of GWS changes due to water and oil depletion ranged from -18.5 to -6.2 $\mathrm{mm} /$ year using the CSR GRACE monthly solutions and the best tested hydrological model in this study. Moreover, our Sentinel-1 SAR data analysis using Persistent Scatterer Interferometry (PSI) method shows high rate of subsidence i.e. -24.5, -23.8, -14.2 and - $6 \mathrm{~mm} / \mathrm{year}$ over Heglig, Neem, Diffra and Unity-area oil fields respectively. The results of this study can help us to control the integrity and safety of operations and infrastructure in that region, as well as to study the groundwater/oil storage behavior. 